\title{
CORRESPONDENCE
}

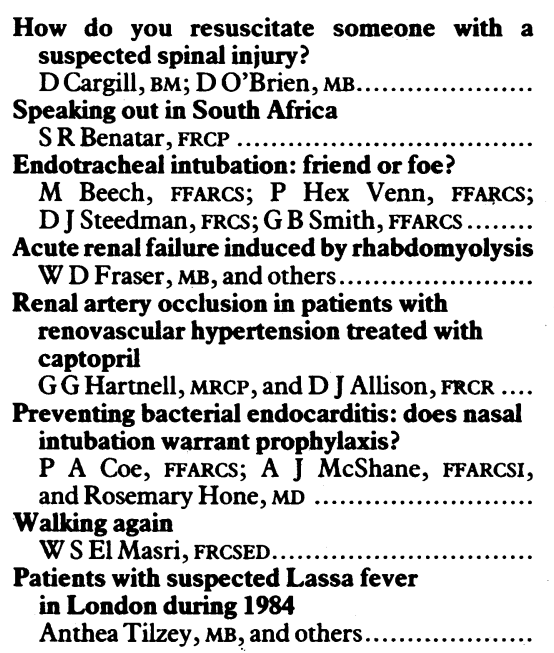

How do you resuscitate someone with a suspected spinal injury?

Speaking out in South Africa

S R Benatar, FRCP

dotracheal intubation: friend or foe?

, FFARCS; $P$ Hex Venn, FFARCS;

D Steedman, FRCS; G B Smith, FFARCS .........

W D Fraser, $M B$, and others.

Dal artery occlusion in patients with

renovascular hypertension treated with

Preventing bacterial endocarditis: does nasal intubation warrant prophylaxis?

P A Coe, FFARCS; A J McShane, FFARCSI and Rosemary

W S EI Masri, FRCSED

in London during 1984

Anthea Tilzey, MB, and others

Doctors and benefits

Ruth Cohen

408

Bioavailability of drugs

T P Delaney, MPSI ...

408 Taking money from the devil

J Dobbing, FRCP

Effect of knowledge of serum enzyme

concentrations on doctors' interpretation of electrocardiographic manifestations in suspected acute myocardial infarction

DH Spodick, $M D$

Informing the hospital of patients' drug regimens

DShort, FRC

Management training for clinicians

T J Wood, MRACP

Massive bladder haemorrhage

P J B Smith, FRCS, and others ..

Patients' access to personal health

information

L A Kirwan, FRCS

Hazards of glass ampoules

H Kawane, MD..
Prevalence of asthma in children under 16

S Head, MRCGP .................................. 412

Yersinia and iron overload

Deirdre Kelly, MRCPI, and others............. 413

Use of ordinal scales in clinical trials

J P Watson, FRCPSYCH....................... 413

Electrolyte disturbances and cardiac failure

with hypomagnesaemia in anorexia nervosa

KO Stewart, MRCP, and others............... 413

411 Doctors and torture

J Havard, MD.

412 Points Treatment of hyponatraemic seizures with intravenous $29 \cdot 2 \%$ saline (P N Robinson and N P Hirsch); The radiologists group and group committee (F W Wright and $M$ Goldman); Vacuum extraction or forceps? (R M Freeman; P Franks); Unexplained acute backache in longstanding ankylosing spondylitis (M I D Cawley); Crime and psychopathology (D F Early); Sexual dyspsychopathology (D F Early); Sexual dys-
function in Asian couples (D Khoosal) ..........
414

Letters critical of a paper may be sent to the authors of the paper so that their reply may appear in the same issue.

We may also forward letters that we decide not to publish to the authors of the paper on which they comment.

Letters should not exceed 400 words and should be typed double spaced and signed by all authors, who should include their main degree.

\section{How do you resuscitate someone with a suspected spinal injury?}

SIR,-An increasing number of people are taking courses in first aid; I taught or examined more than 400 such people last year. Although most of them are keen and intelligent, few have even an elementary knowledge of human biology. They therefore have to accept my teaching as dogma and give similar credence to "the authorised manual" of St John Ambulance, St Andrew's Ambulance Association, and the British Red Cross Society.

The manual says (p 35), "Any unconscious casualty should be placed in the recovery position immediately." Pictures of the ordinary and modified recovery positions (p 25 and 41 ) show the head and neck twisted out of alignment with the thoracic spine and with one another. The manual also says (p 111 on skull fractures), "If any discharge issues from the ear incline the head towards the injured side. . . ."

$\mathrm{Mr}$ Andrew Swain and his colleagues (30 November, $p$ 1158) point out that any injury which has caused unconsciousness must be presumed to have caused spinal injury also, a point not mentioned in the manual. In their letter (11 January, $p$ 139) they advise a supine position for those who are conscious or intubated, a lateral position for the unconscious. Dr Andrew $\mathrm{K}$ Marsden and others (p 138) suggest "the stable position with the head and chest in one line" after the patient has been carefully rolled on to one side. Dr Andrew Raffle and others (p 139) say that "the view of St John Ambulance is that the prospect of spinal injury should be entertained in all traumatic cases of unconsciousness" and they advise a careful turn into "a stable side-position with the head remaining in neutral. ..." Like Mr Swain and colleagues I cannot find this in the manual.

I am troubled by the fact that while the recovery position is stable, maintaining itself in the absence of any support other than the ground or a stretcher, a lateral position with the head and neck neutral is unstable: indeed it is difficult to maintain for more than a few minutes when conscious, uninjured, and not being jolted about during an ambulance journey or a hand carry.

So what am I to teach my candidates for the first aid certificate? If there are four of them they could attempt the lateral and head neutral position but in other cases they may have to go back to the manual, use the recovery position, and hope that the spine can look after itself. This seems to be the gist of $\mathrm{Dr}$ Rowland L Cottingham's advice (p 139).

\section{Maldon,}

Essex CM9 7P

\section{David CARGILL}

SIR,-In their thought provoking contribution (30

November, $\mathrm{p}$ 1558) $\mathrm{Mr}$ Andrew Swain and colleagues have reversed the customary first aid doctrine that-obvious contraindications apart -all unconscious casualties must be placed in the recovery position. They base their challenge on an assumption-unsupported by corroborating evidence - "that the force that rendered the patient unconscious has injured the cervical spine until proved otherwise by radiography." While it is right to emphasise the possibility of an unstable fractured spine in an unconscious casualty, first aiders must be taught to act according to probabilities; the fact is that the vast majority of head injuries do not have concomitant spinal fractures.

One appreciates that the article was written for doctors called to the scene in a well equipped ambulance, and first aiders are advised not to move a casualty if such help is close at hand, but to suggest that the approach should then be so different from that of the isolated lay first aider must invite confusion. Undoubtedly it is easier to control the head in the supine position but, as the writers say, if vomiting occurs (perhaps stimulated by an oropharyngeal airway) the patient may have to be turned on his side-and many will have observed the precipitate, even panicky, manoeuvre which imminent vomiting tends to initiate.

The British Red Cross Society teaches that the airway has priority over all other considerations. If spinal injury is suspected, the casualty should be $\log$ rolled in one piece, head held in neutral position by one first aider, into the semiprone recovery position. To avoid rotation or other movement the head should be controlled by gentle traction throughout any ambulance journey.

The "lateral position" is not recommended; it is unstable, unless the arms are pulled well forwards, and dangerous for stretcher carriage, especially when loading into an ambulance.

The writers make a further assumption (11 January, p 139)-impossible to prove or disprove - that in the single case quoted, the outcome would have differed had the patient been managed supine. Have they forgotten the oft seen patient who moves all limbs in the $x$ ray department but, however carefully managed, is tetraplegic or paraplegic by nightfall?

Caution in handling the unconscious casualty is admirable but, in absorbing too many caveats, it may be the first aider who becomes paralysed while the casualty chokes to death.

British Red Cross Society,

D D O'BRIEN Chief Medical Adviser London SW1X 7EJ

\section{Speaking out in South Africa}

SIR,-Dr H Bloem (12 October, p 1052) expresses concern about the treatment of people injured during civil unrest. He questions "whether the South African medical profession has learnt any- 
thing from the Biko affair" and in relation to treatment of injuries received during civil unrest whether "the deafening silence of South African doctors means that once again they are prepared to condone the excesses of the South African state."

His concern about the treatment of people injured during civil unrest is shared by many health professionals in South Africa. It would not be fair or appropriate to leave the impression that concern about this, and other issues relevant to the delivery of equitable and ethical medical care, has not been strongly voiced by doctors and medical faculties dedicated to providing medical care of the highest ethical standard despite restrictions imposed by abhorrent discriminatory policies.

The appended incomplete list of references illustrates this. ${ }^{1-15}$

S R BENATAR

University of Cape Town Medical School,

Cape Town

South Africa

1 Benatar SR. The death of Dr Neil Aggett. $S$ Afr Med $\mathcal{f}$ 1982;61:300.

2 Benatar SR. Medical ethics and political ideology. S Afr Med f 1982;61:420.

3 McKenzie D. Medical treatment of prisoners and detainees. $S$ Afr Med f 1982;61:688.

4 Ad Hoc Committee of the Medical Association of South Africa to Institute an Inquiry into the Medical Care of Prisoners and to Institute an Inquiry into the Medical Care of Prisoners and Detainees. Medical care of

de Villiers JC, et al. The medical care of prisoners and detainees. $S$ Afr Med f 1983;64:116-8.

6 Currin MR. The medical care of prisoners and detainees. $S$ Afr Med F 1983;64:300.

7 Kirsch R. The Cape Town squatter community-problems and health care perspectives. $S$ Afr Med f 1983;64:690.

8 Dean and Executive Committee, Faculty of Medicine, University of Cape Town. The Cape Town squatter community - problems and health care perspectives. S Afr Med $\mathcal{J}$ 1983;64:690.

9 Gluckman J. Civil disorder and the doctor's duty. S Afr Med J 1985;68:64-5.

10 Dall G. Medical ethics and civil strife. S Afr Med f 1985;68:133.

11 Dall G. Medical care of detainees. $S$ Afr Med $\mathcal{7}$ 1985;68:133.

12 Saunders SJ. Civil disorder and the doctor's duty. S Afr Med I 1985;68:288.

13 Silbert MV, Grindley-Ferris M. Support for Wendy Orr. $S$ Afr Med f 1985;68:705.

14 Levenstein JH. Medical treatment of detainees. $S$ Afr Med $\mathcal{J}$ 1985;68:839.

15 Benatar SR. A national health service for South Africa. $S$ Afr Med f 1985;68:839.

\section{Endotracheal intubation: friend or foe?}

SIR,-Dr D B Scott's final recommendation in his excellent leading article on endotracheal intubation (18 January, $p$ 157) is that the tube should be left in situ for subsequent verification of placement by the pathologist. I disagree with this and always remove the tube after death. My reasons for this are twofold.

Firstly, there is no guarantee that the tube will remain in the position it was left in by the anaesthetist. I have seen an endotracheal tube accidentally pulled out of a cadaver and blindly reinserted into the oesophagus. If I had not seen this the anaesthetist might have been wrongly blamed for the oesophageal intubation. Secondly, the relatives often want to view the body, and the disfigurement caused by the tube may considerably aggravate their distress.

My approach to the problem is to hand a laryngoscope to another doctor and ask him to verify the position of the tube and record his findings in the notes. I then remove the tube.

London SE24 9QY

MichaEL BEECH

SIR,-Dr D B Scott draws attention to the difficulty of teaching intubation to the inexperienced.

I have found that it is as difficult to train the would be resuscitator to inflate the patient with a face mask as it is to intubate, since in many people, especially the elderly, who may be edentulous with blocked nasal passages, it is impossible to inflate the lungs without inserting an airway. Even then, because in the adult there is an infinite variety of facial contours, it may be very difficult to teach how to achieve an effective seal, particularly in the presence of a beard and when the trainee is a nurse with a tiny hand. Most anaesthetists overcome this difficulty by opening the oxygen bypass and blasting $50 \mathrm{l} / \mathrm{min}$ of oxygen into the face mask, thus effectively compensating for any leaks. During resuscitation, however, if oxygen is not available the tidal volume will depend solely on the capacity of the self inflating bag, usually $600-700 \mathrm{ml}$.

The "Sussex Valve Airway" (available from Tandisdale Medical, Forest Row, East Sussex RH18 5AA), a new piece of apparatus designed to make mouth to mouth resuscitation more effective, comes with an airway insert that accepts a 22 $\mathrm{mm}$ taper and attached to a silicone rubber sealing flange. By inserting a face mask angle directly into the airway insert a good seal can easily be maintained. Indeed, this might well be the method of choice for routine preinflation of the patient at the start of anaesthesia because even an experienced

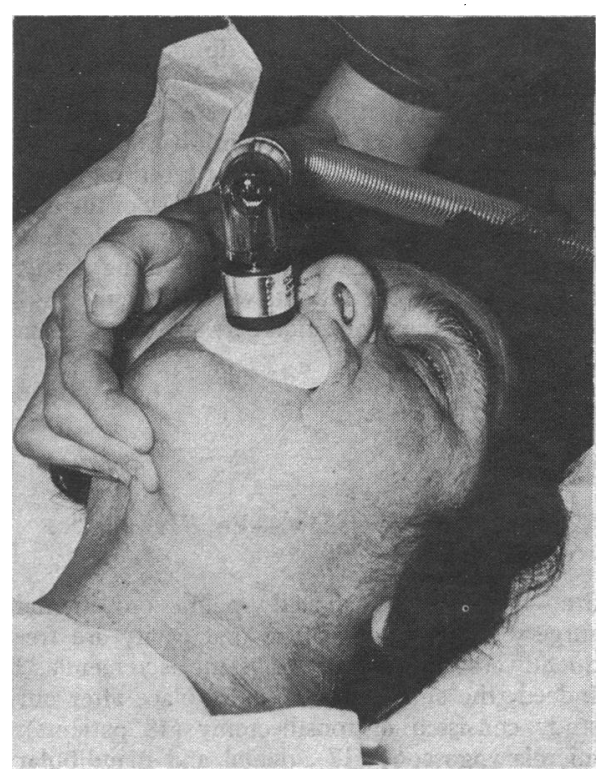

Sussex Valve Airway in use.

operating department assistant finds that the technique requires less concentration than when using a face mask; the grip can even be released altogether, requiring just three fingers to support the chin (see figure). Curiously, there is seldom any significant gas leak through the nose.

P HEX VENN

District General Hospital

Eastbourne BN21 2UD

SIR,-Dr D B Scott correctly emphasises the dangers that may arise when endotracheal intubation is executed by the inexperienced (18 January, p 157). He expresses concern about resuscitation of an unanaesthetised patient after cardiovascular collapse; as he points out, intubation is now considered an essential part of cardiopulmonary resuscitation, "even when no anaesthetist is present."

Cardiopulmonary resuscitation is commonly performed in the accident and emergency department, and, although some departments still rely on outside cardiac arrest teams, favourable results can be obtained by experienced accident and emergency staff. In our own department, where endotracheal intubation is routinely used to facilitate artificial respiration and safeguard the airway during the management of cardiopulmonary arrest, the long term survival (those patients who leave hospital alive) is over $25 \%$. $^{1}$

While Dr Scott acknowledges that some doctors who have had no anaesthetic training can pass tubes, I would agree that the skill is one which requires continuous practice-as, for example, in an accident and emergency department.

Cardiac arrest teams often comprise junior anaesthetic staff, working in unfamiliar surroundings. Experienced accident and emergency staff, who are rehearsed in the management of the acutely ill and injured and who are familiar with the layout and equipment used in the department, form a more appropriate team. Perhaps in this way the resultant complications and deaths from endotracheal intubation might be minimised.

Dr Scott is also emphatic that non-anaesthetists should use mouth to mouth respiration as the primary intervention in cardiopulmonary collapse. Surely this is inappropriate in hospital, particularly in the accident and emergency department; bag to mouth ventilation may be used as the temporising measure until endotracheal intubation is established.

Accident and Emergency Department,

David J STEEDMAN

Royal Infirmary,

Edinburgh EH3 9YW

1 Robertson CE, Little K. Cardiopulmonary resuscitation in the accident and emergency department. Archives of Emergency Medicine 1984;1:17-22.

SIR,-Endotracheal intubation at cardiac arrests is often desirable but not essential. Repeated attempts at intubation without intermittent pause for oxygenation may prejudice survival instead of increasing its chances. It is therefore unfortunate that repeated efforts to insert an endotracheal tube during cardiopulmonary resuscitation, often by people unskilled in the technique, have become common.

Reversal of such "bad practice" and the need to instil commonsense priorities into the management of patients suffering cardiopulmonary arrest can occur only if there is an improvement in the education of medical students. I am often approached by medical students or members of the house staff with a request to be taught how "to intubate" as it is rightly seen as a useful practical procedure. Few, if any, students, however, ask for training in basic airway management or oxygen therapy and most seem to have misunderstood the priorities of managing airway obstruction or apnoea. The failure to recognise that ventilation of the lungs is not synonymous with intubation of the trachea is common and the appreciation that simple methods of airway control may suffice is often lacking.

The medical profession must look critically at the training it provides in resuscitation. At present many doctors and medical students get no formal training in airway management, oxygen therapy, intubation, or defibrillation. Contrast this lack of training with the high standard expected of advanced trained ambulance personnel. Candidates are given in hospital training in practical procedures under direct supervision by clinicians, and successful completion of the course requires formal assessment. Those candidates who fail to reach desired standards are prevented from using these special skills on the general public until they improve their performance. No such safeguards exist for junior doctors.

As Dr Scott comments, "Patients do not die from a failure to intubate. They die either from 